\title{
A medicalização da vida escolar: incoerências na conceituação do TDAH
}

\section{The medicalization of school life: incoherencies in the conceptualization of TDAH}

\section{La medicalización de la vida escolar: incoherencias en la conceptualización del TDAH}

\author{
Mayara Karolina Alvarenga Recaldes Gomes Coutinho ${ }^{1}$ \\ Doracina Aparecida de Castro Araujo ${ }^{1}$
}

DOI: http://dx.doi.org/10.20435/serie-estudos.v23i47.959

\begin{abstract}
Resumo: Artigo de revisão bibliográfica sobre a medicalização da Educação a partir da queixa de déficit de atenção e hiperatividade proveniente da escola e demandante de diagnóstico médico e/ ou psicológico. O objetivo deste artigo é apresentar a contribuição de autores nacionais e latino-americanos à crítica da medicalização da vida e do processo ensino-aprendizagem, marcado pelas explicações biológicas sobre o comportamento do aluno, especialmente daquele identificado como desatento e/ou inquieto sobre o qual se apõe o diagnóstico de Transtorno do Déficit de Atenção e Hiperatividade (TDAH). O material para análise foi selecionado pelo critério de relevância de autoria, a partir da busca em artigos e capítulos de livros que tinham como tema principal medicalização e TDAH. A análise qualitativa permite concluir que a medicalização está inserida no processo de biologização da vida e corresponde à transposição das explicações próprias do campo médico para as questões inerentes a outros campos, como a Educação. Quanto ao TDAH, trata-se de um transtorno mental que materializa a medicalização da Educação e sobre o qual ainda não há um consenso teórico. São apontadas, ainda, as incoerências internas nos critérios diagnósticos do TDAH erigidos pelo Manual diagnóstico e Estatístico de Transtornos Mentais e algumas implicações da medicalização para o sujeito diagnosticado e para o contexto escolar.
\end{abstract}

Palavras-chave: medicalização; TDAH; educação.

\begin{abstract}
Article of bibliographic review about the medicalization of Education from the complaint of attention deficit hyperactivity disorder proceeding from the school and demanding a medical and/or psychological diagnosis. The aim of this article is to present the contribution of national and Latin-American authors to the critique of the medicalization of life and the teaching-learning process, marked by biological explanations about the student's behavior, especially that identified as inattentive and/or unquiet about which affixes to the diagnosis of Transtorno do Attencion Deficit Hiperacitivity Disorder (TDAH). The material for analysis was selected by criteria of relevance of
\end{abstract}

\footnotetext{
${ }^{1}$ Universidade Estadual de Mato Grosso do Sul (UFMS), Paranaíba, Mato Grosso do Sul, Brasil.
} 
authorship, from the search in articles and book chapters that had as its main theme medicalization and TDAH The qualitative analysis shows that the medicalization is inserted in the biologization process of life and corresponds to the transposition of own explanations of the medical field to the issues inherent in other fields, such as Education. About the TDAH, it is a mental disorder that materializes the medicalization of Education and about which there isn't still a theoretical consensus. It is pointed out, also, internal incoherencies in the TDAH diagnostic criteria erected by the Diagnostic and Statistical Manual of Mental Disorders and some implications of the medicalization to the individual diagnosed and to the school context.

Keywords: medicalization; TDAH; education.

Resumen: Artículo de revisión bibliográfica sobre la medicalización de la educación a partir de la queja de déficit de atención e hiperactividad proveniente de la escuela y demandante de diagnóstico médico y / o psicológico. El objetivo de este artículo es presentar la contribución de autores nacionales y latinoamericanos a la crítica de la medicalización de la vida y del proceso enseñanza-aprendizaje, marcado por las explicaciones biológicas sobre el comportamiento del alumno, especialmente de aquel identificado como desatento y / o inquieto sobre el cual se apunta el diagnóstico de Trastorno del Déficit de Atención y Hiperactividad (TDAH). El material para análisis fue seleccionado por el criterio de relevancia de autoría, a partir de la búsqueda en artículos y capítulos de libros que tenían como tema principal medicalización y TDAH. El análisis cualitativo permite concluir que la medicalización está inserta en el proceso de biologización de la vida y corresponde a la transposición de las explicaciones propias del campo médico para las cuestiones inherentes a otros campos, como la Educación. En cuanto al TDAH, se trata de un trastorno mental que materializa la medicalización de la Educación y sobre el cual aún no hay un consenso teórico. Se señalan, además, las incoherencias internas en los criterios diagnósticos del TDAH erigidos por el Manual diagnóstico y Estadístico de Trastornos Mentales y algunas implicaciones de la medicalización para el sujeto diagnosticado y para el contexto escolar.

Palabras clave: medicalización; TDAH; educación.

\section{INTRODUÇÃO}

A medicalização da vida e, mais especificamente, a forma como afeta as relações humanas estabelecidas no interior da escola têm ocupado a agenda atual de profissionais e pesquisadores, os quais, em muitos casos, acabam trilhando, em suas pesquisas e atuação profissional, um caminho de militância e denúncia ao crescente processo de biologização da vida. Este artigo tem o objetivo apresentar a contribuição de autores nacionais à crítica da medicalização da vida e do processo ensino-aprendizagem, marcado pelas explicações biológicas sobre o comportamento do aluno, especialmente daquele identificado como desatento e/ou inquieto e, muitas vezes, diagnosticado com Transtorno do Déficit de Atenção e Hiperatividade (TDAH). Foi empregada a metodologia da revisão bibliográfica com análise qualitativa dos resultados. Assim, é apresentada a definição 
de medicalização, um breve histórico da construção do Manual Diagnóstico e Estatístico de Transtorno Mentais (DSM), como manual norteador das condutas médicas e psicológicas no campo da saúde mental, e as diretrizes erigidas por este manual para o diagnóstico do TDAH, bem como as críticas atuais de autores nacionais e latino-americanos tanto ao DSM quanto ao TDAH enquanto entidade nosológica e as implicações da medicalização no processo ensino-aprendizagem.

De acordo com Collares e Moysés (2011), a medicalização do processo ensino-aprendizagem é reflexo de um processo mais amplo, o de biologização da vida, isto é, na transformação de questões sociais em questões biológicas, respaldado numa ciência de matriz positivista, nomeada pelas autoras como uma ideologia. Com isso, o processo saúde-doença é reduzido a questões de funcionamento biológico do corpo, e os conflitos decorrentes dos contextos histórico, cultural e social em que os sujeitos estão inseridos são silenciados, na mesma medida em que esses sujeitos são culpabilizados pela própria condição de vida em que se encontram. Na escola, esse fenômeno se observa na busca das causas das dificuldades no processo ensino-aprendizagem e do fracasso escolar em características inerentes aos alunos e, como consequência, a discussão político-pedagógica do processo ensino-aprendizagem é deslocada para causas e soluções pretensamente médicas, logo, inacessíveis à Educação, uma vez que supostamente estão fora de seu escopo de discussão e atuação (COLLARES; MOYSÉS, 2011).

A medicalização da vida, entendida "como expressão da difusão do saber médico no tecido social [...] como uma operação de práticas médicas num contexto não terapêutico, mas político-social" (GUARIDO, 2011, p. 30), não é recente e foi estudada por vários autores, como Illich (1975) e Foucault (1980) citados por Collares e Moysés (2011). No Brasil, a medicalização é objeto de estudo de profissionais e pesquisadores de diversas áreas do conhecimento. As discussões acerca da medicalização da vida culminaram na organização, em 2010, do Fórum sobre Medicalização da Educação e da Sociedade, que tem os objetivos de "articular entidades, grupos e pessoas para o enfrentamento e superação do fenômeno da medicalização, bem como mobilizar a sociedade para a crítica à medicalização da aprendizagem e do comportamento" (CONSELHO FEDERAL DE PSICOLOGIA [CFP], 2012, p. 6). O Conselho Federal de Psicologia é um dos órgãos integrantes do Fórum e, fazendo referência às diversas edições do DSM, publicado pela Associação Psiquiátrica Americana (APA), define a medicalização 
como "processo que transforma questões de ordem social, política, cultural em 'distúrbios', 'transtornos', atribuindo ao indivíduo uma série de dificuldades que o inserem no campo das patologias, dos rótulos, das classificações psiquiátricas" (CFP, 2012, p. 6).

Para o campo educacional, a medicalização se apresenta na patologização do processo ensino-aprendizagem e, assim, de acordo com a referida publicação:

[...] ter dificuldade de leitura e escrita não mais questiona a escola, o método, as condições de aprendizagem e de escolarização. Mas sim, busca na criança, em áreas de seu cérebro, em seu comportamento manifesto as causas das dificuldades de leitura, escrita, cálculo e acompanhamento dos conteúdos escolares. A criança com dificuldades em leitura e escrita é diagnosticada, procuram-se as causas, apresenta-se o diagnóstico e em seguida a medicação ou o acompanhamento terapêutico. (CFP, 2012, p. 7).

Nota-se, assim, a apropriação das ciências médicas e da Psicologia pelo contexto escolar, consonante com a racionalidade científica moderna que postula uma visão naturalista, ou seja, mecanicista e organicista do homem e da sociedade para, pretensamente, explicar a razão do não aprender (WERNER JÚNIOR, 2007, p. 70). E a explicação dada desresponsabiliza a instituição escolar ao negar os conflitos inerentes à sociedade capitalista.

De acordo com Saviani (2003), os sistemas escolares embora banhados em uma ideologia de promoção da igualdade entre os homens ao possibilitar o acesso dos alunos ao acervo cultural da humanidade, tem-se constituído enquanto local de produção de desigualdades e de manutenção do status quo, uma vez que responde à contradição inerente ao sistema capitalista. Nesse sentido, a medicalização vem contribuir ao propor uma justificativa para as desigualdades de desempenho entre os alunos, apontando para a referência ao corpo perfeito, ao denominado social e historicamente como o normal, o socialmente aceitável.

Para Guarido (2011), na atualidade o determinismo biológico tem-se tornado hegemônico e oferecido o parâmetro para o funcionamento normal do corpo dos alunos. Assim, revestido de uma pretensa cientificidade, o discurso médico-psicológico é apropriado no cotidiano escolar "tanto na suspeita de um diagnóstico, como na demanda para que ele se realize" (GUARIDO, 2011, p. 35). Para a autora, a história desse processo remete à concepção de infância forjada na modernidade e na concepção da escola como espaço de transformação dos infantes em indivíduos capazes para o trabalho e psiquicamente saudáveis para participação social. 
Nesse sentido, as consequências da hegemonia do determinismo biológico podem ser observadas tanto no campo da saúde mental como no campo escolar. Na saúde mental, o determinismo biológico sustenta "uma racionalidade médica que tende à pesquisa de evidências, à objetivação dos sinais sintomáticos e ao uso de medicamentos psicotrópicos como eixo fundamental de tratamento dos sofrimentos humanos" (GUARIDO, 2011, p. 30). Isso desloca o sujeito da análise de seu sintoma, uma vez que o sinal, isto é, a manifestação sintomática, é valorizado em detrimento daquilo que o sujeito tem a dizer sobre si, sobre a história de vida que levou à construção de determinado quadro clínico. O sintoma é, então, tomado como um sinal de desvio ou de doença, que deve ser eliminado a partir de uma ortopedia psicotrópica e não é escutado.

No campo educacional, além da demanda por diagnósticos, o determinismo biológico anima a busca por uma metodologia de ensino baseada nos resultados de pesquisas sobre o funcionamento cerebral, e o aprendizado é entendido como resultado da correta estimulação do cérebro, ou seja, a aprendizagem é reduzida a uma dimensão privada, individual. Com isso, a dimensão simbólica da subjetividade, a transmissão simbólica que afeta o organismo, que só é possível ser alcançada no encontro e enlace com o outro é desconsiderada, e a aprendizagem "perde o caráter de ser fruto da ação humana, dimensão do encontro na pluralidade do mundo público, onde produzimos história" (GUARIDO, 2011, p. 37).

Para a autora consultada, o efeito da medicalização do processo ensino-aprendizagem pode ser observado na

retirada da possibilidade de atuação dos sujeitos sobre o que lhes acontece, já que os problemas e condições do aprendizado das crianças estariam dados pelo funcionamento cerebral e não pelas interferências de um outro em sua condição de estruturação e desenvolvimento. [com isso] Crianças e adultos, confrontados com certa desresponsabilização sobre o que lhes acontece tornam-se também impotentes para atuarem sobre seus sofrimentos e aprendizados. (GUARIDO, 2011, p. 36-7).

Assim é deslocado o eixo de ação dos sujeitos do espaço social para o interior do indivíduo, e as vicissitudes das relações humanas são tomadas como efeito do funcionamento bioquímico do organismo. Como consequência, ocorrem a desresponsabilização e a impotência das crianças, famílias e professores diante de um diagnóstico referendado cientificamente conforme as delimitações do Manual Diagnóstico e Estatístico de Transtornos Mentais (DSM). 


\section{A DEFINIÇÃO CIENTÍFICA PARA O TDAH: AS CONTRADIÇÕES DO DSM-IV}

O DSM é um manual de psiquiatria criado e editado periodicamente pela Associação Psiquiátrica Americana (APA). O referido manual despontou como resposta à necessidade de estabelecerem-se novos diagnósticos e novos tratamentos aos sobreviventes da guerra e à população civil, depois da Segunda Guerra Mundial. Até então, a psiquiatria norte-americana seguia os critérios da psiquiatria clássica e da Psicanálise para os diagnósticos. Nesse contexto, o DSM apareceu em 1952 como um instrumento confiável de referências compartilhadas entre os profissionais de saúde mental (FENDRIK, 2011).

Considerando o acolhimento ofertado aos psicanalistas pelos Estados Unidos da América durante a Segunda Guerra Mundial, a primeira edição do DSM apresentava critérios diagnósticos influenciados pela Psicanálise; esse dado se faz importante, uma vez que uma das marcas desse referencial teórico é a escuta dos sujeitos. Entretanto, com a crescente influência do referencial comportamentalista, ou behaviorista, o qual enfatiza o estudo do comportamento observável, a escuta dos sujeitos nos moldes psicanalíticos paulatinamente se constituiu como obstáculo à objetividade científica pretendida pelo DSM. Assim, na edição subsequente do manual, as contribuições psicanalíticas diminuíram e desapareceram de vez na terceira edição, substituídas por "sinais visíveis que 'falam' por si mesmos sem a necessidade de que o paciente diga nada" (FENDRIK, 2011, p. 30).

Nessa esteira de considerações, recorremos a Izaguirre (2011) quando este autor afirma que a quarta edição do manual exclui o critério nosográfico, desconsiderando a existência de doenças mentais - uma vez que a doença pressupõe não só sintomas, mas também uma etiologia, isto é, uma explicação para os sintomas - em favor do conceito de transtornos mentais. Assim, o critério enfatizado é o estatístico, o que possibilita a transformação do DSM num manual classificatório que, supostamente, não tem a necessidade de considerar as diferentes orientações teóricas dos profissionais de saúde mental, pois fornece uma classificação empírica das categorias, baseada na observação e medição dos sinais dos transtornos mentais, porém sem apontar para a definição destes.

Destarte, essa classificação empírica oferece "sinais e itens observáveis e, consequentemente, medicalizáveis" (FENDRIK, 2011, p. 31). A autora, então, conclui que as mudanças no DSM que geraram as quatro edições, suas revisões 
e, acrescentamos, mais recentemente a quinta edição do DSM em 2013, foram produzidas para encontrar sinais de transtornos cada vez "mais objetivos, mais observáveis, mas mensuráveis e em maior quantidade" (FENDRIK, 2011, p. 31). Consequentemente, houve a proliferação dos transtornos como pode ser observada no crescente número de páginas do DSM a cada nova edição, de 150, da segunda edição, para 500 páginas, na terceira edição revisada e para 900 páginas, na quarta edição, texto revisado, que vigora atualmente.

Fendrik (2011), ao analisar a história do DSM e criticar sua "metafísica fenomenológica", chama atenção ainda para o conceito de normalidade subjacente ao manual psiquiátrico, mas não revelado, já que este se pretende um manual a-teórico, baseado na realidade do observado e na neutralidade do observador. Segundo a autora consultada, o DSM não deixa claro qual é o padrão esperado no qual se baseiam os desvios, os transtornos que descreve, entretanto o estudo das categorias arroladas no manual apontam que o não esperado, aquilo que foge à norma, é avaliado em relação às expectativas do modo de vida americano:

As estatísticas estabeleceram, em contrapartida, que as crianças provenientes das classes baixas, ou 'transculturadas', podem não aprender ou ser atacadas por múltiplos transtornos, que contaminarão cedo ou tarde aqueles de quem se espera que respondam às expectativas do amerian-way-of-life, o sistema de valores que os Estados Unidos conseguiram impor ao Ocidente a partir da Segunda Guerra Mundial como o único respeitável. (FENDRIK, 2011, p. 33).

Nesse sentido, vale a referência de que, há muito, o uso do DSM escapou ao controle da Psiquiatria, difundindo-se entre os mais diversos contextos que lidam diretamente ou não com a saúde mental, uma vez que classifica transtornos do comportamento humano que se manifestam onde quer que os humanos atuem. É o caso dos transtornos de aprendizagem e outros transtornos mentais com início na infância, que invariavelmente deveriam implicar a escola, mas capturam os professores e os fazem extensão do especialista na escola, demandando diagnósticos e auxiliando na execução dos tratamentos - como na supervisão do uso de medicamentos, por exemplo.

Isso traz implicações importantes para o processo ensino-aprendizagem tanto dos alunos que se constituem Público-alvo da Educação Especial (PAEE) ${ }^{2}$

\footnotetext{
${ }^{2}$ Terminologia utilizada no Decreto n. 7.611, de 17 de novembro de 2011, Art. 1ㅇ․
} 
(alunos com deficiências, transtornos globais do desenvolvimento e altas habilidades/superdotação), como daqueles que têm dificuldades escolares e, ao passarem por um processo de avaliação diagnóstica, são identificados como pessoas com algum transtorno mental ou de aprendizagem.

Aqui se faz importante discorrer sobre o Transtorno do Déficit de Atenção e Hiperatividade (TDAH), transtorno mental com diagnóstico crescente nos últimos anos, alvo de numerosos debates científicos, identificado por pesquisadores críticos como um dos (não tão) novos transtornos em que a medicalização da educação se materializa. A quarta edição revisada do DSM (DSM-IV-TR) ${ }^{3}$ coloca o TDAH na seção Transtornos geralmente diagnosticados pela primeira vez na infância ou adolescência, capítulo dos Transtornos de Déficit de Atenção e Comportamento Disruptivo, ao lado do Transtorno de Conduta, Transtorno Desafiador de Oposição e do Transtorno de Comportamento Disruptivo sem outra especificação.

Conforme o referido manual, o TDAH é um transtorno relacionado ao desenvolvimento caracterizado por um trio de sinais e sintomas: dificuldades de atenção, hiperatividade e impulsividade, os quais podem se manifestar de forma isolada ou coexistir. No quadro clínico do TDAH, os sinais de desatenção, hiperatividade e impulsividade apresentam-se desde a infância - antes dos sete anos de idade - de forma inapropriada do ponto de vista desenvolvimental, como manifestações que não são esperadas no estágio maturacional em que o sujeito se encontra (APA, 2002).

A desatenção é entendida como uma dificuldade no planejamento e execução das atividades e no iniciar, manter-se engajado e concluir uma tarefa. Observam-se ainda: dificuldade de organização, distratibilidade, dificuldade em escutar o que é dito, esquecimentos de compromissos e objetos, além de alterações na noção de tempo, levando à procrastinação, especialmente no caso de adolescentes e adultos (APA, 2002; POLANCZYK; ROHDE, 2012).

De acordo com o DSM-IV, a hiperatividade refere-se ao excesso de atividade física e a um sentimento de inquietude, o que impossibilita ao sujeito permanecer inativo quando isso é esperado pelo meio em que ele está. A hiperatividade, no caso do TDAH, não está relacionada a uma determinada tarefa, nem tem um

\footnotetext{
${ }^{3}$ Em 2016 foi publicada, no Brasil, a quinta edição do DSM (APA, 2016), que apresenta algumas alterações relativas ao diagnóstico do TDAH, as quais, no entanto, não invalidam as críticas apresentadas neste artigo.
} 
propósito específico, e afeta de forma negativa o ambiente. Já a impulsividade é referida à dificuldade de adiar uma ação ou resposta, mesmo diante da antecipação das possíveis consequências negativas mediante tal ação ou resposta. A hiperatividade está associada à necessidade de obter gratificação imediata observada em sujeitos que têm uma incapacidade para adiá-las até que avalie a situação que se apresenta (APA, 2002; POLANCZYK; ROHDE, 2012).

Para o diagnóstico do TDAH - realizado de forma clínica, já que de acordo com o DSM-IV, ainda não existem exames laboratoriais com resultados conclusivos para o diagnóstico - os sinais de desatenção, hiperatividade e impulsividade precisam se manifestar de forma intensa e persistente ao longo do tempo, trazendo prejuízos funcionais importantes para o sujeito, como dificuldades escolares, no caso de crianças e adolescentes, e claras interferências no funcionamento social e ocupacional (APA, 2002). O TDAH pode ainda ser classificado segundo os subtipos combinados, predominantemente desatento ou predominantemente hiperativo-impulsivo, definidos com base no número de sintomas predominantes nos seis meses que antecedem ao diagnóstico, conforme o quadro a seguir, reproduzido consoante se apresenta no manual. 


\section{Critérios Diagnósticos para Transtorno de Dé ficit de A tenção e Hịper atividade}

A. Ov (1) ov (2)

(1) Seis (ov mais) dos seguintes sintomas de desatenção persistiram pelo perído minimo de 6 meses, em grav mal adaptativo e inconsistente com o nivel de desenvolviment:

\section{Desatenço:}

(a) Frequentemente nảo presta atençâo a detathes ov comete erros por omissảo em atividades escolares, de trabatho ov outras

(b) Com frequência em dificuldade pera manter a atenção em tarefas ov atividades lidicas

(c) Com frequência parece nảo ouvir quando the dirigem a palayra

(d) Com frequência nảo segve instruçòes e nảo ermina seus deveres excolares, tarefas domésticas ov deveres profissionais (não devido a comportamento de oposição ov incapacidade de compreender instruçòes)

(e) Com frequência em dificuldade para or ganizar tarefas e atividades

(f) Com frequência evita, demonstra ojeriza ou retuta em envolver-se em tarefas que exigem esforço mental constante (como tarefas escolares ov deveres de casa)

(g) Com frequência perde coisas necessárias para tarefas ov atividades (p.ex., brinquados, tarefas escolares. lapis, livros ou outros materiais)

(h) E facilmente distraido por estimulos atheios à tarefa

(i) Com frequência apresenta esquecimentos em atividades diárias

(2) Seis (ou mais) dos seguintes sintomas de hiperativida de persistiram pelo periodo minimo de 6 meses, em grau mal adaptativo e inconsisente com o nivel de desenvolviment:

Hiperatividade:

(a) Frequentemente agita as mãos ou os pés ov æe remexe na cadeira

(b) Frequentemente abandona sua cadeira na sala de aula ou outras sitwações mas quais se espera que permaneça sentado

(c) Frequentemente corre ov escala com demasia, em sitwaçōes impróprias (em adolescentes e adultos, pode estar limitado a sensaçōes subjetivas de inquietaçảo)

(d) Com frequência tem dificuldade para brincar ou se envolver silenciosamente em atividades de lazer

(e) Está frequentemente "a mil" ou muitas vezes age como se estivesse "a todo vapor"

(f) Frequentemente fala em demasia

Inpulsividade

(g) Frequentemente dá respostas precipitadas antes que as perguntas terem sido completamente formuladas

(h) Com frequência tem dificuldade para aguardar sua vez

(i) Frequentemente interrompe ov se intromete em assuntos atheios (p.ex., em conversas ov brincadeiras)

B. Alguns sintomas de hiperatividade-impulsividade ov desatenção causadores de comprometimento estavam presentes anes dos 7 anos de idade.

C. Algum comprometimento cavsado pelos sintomas está presente em dois ou mais contextos (p.ex., na escola [ou trabatho] e em casa).

D. Deve haver claras evidências de um comprometimento clinicamente importante no funcionamento social, acadêmico ou ocupacional.

E. Os sintomas não ocorrem exclusivamente durante o curso de um Transtomo Global do Desenvolvimento, Esquizofrenia ov ovtro Transtomo Psicótico, nem sảo melhor explicados por outro transtorno mental [...]

Quadro 01 - Critérios diagnósticos para TDAH

Fonte: DSM-IV-TR (APA, 2002, p. 118-9, grifos nossos - sublinhados). 
Alguns apontamentos se fazem necessários diante da consulta ao capítulo sobre TDAH no DSM-IV. Primeiro, embora o manual apresente a descrição das características diagnósticas, em momento algum são apresentados o modo como os sintomas foram observados, o modo como o diagnóstico foi realizado e a referência aos estudos que embasam a afirmação de tais sintomas como um transtorno. Outro ponto interessante da publicação é que, embora apresente os sintomas de um transtorno mental, pressupondo que o defeito se encontra no sujeito diagnosticado, não permite definir a etiologia do transtorno, pois, contraditoriamente, afirma que

Os sinais do transtorno podem ser mínimos ou estar ausentes quando o indivíduo se encontra sob um controle rígido, encontra-se num ambiente novo, está envolvido em atividades especialmente interessantes, em uma situação a dois (p.ex. no consultório médico) ou enquanto recebe recompensas frequentes por um comportamento apropriado. (APA, 2002, p. 113).

Tal afirmativa abre margem para questionamentos, por exemplo, se trata de um transtorno da criança ou do ambiente que a circunda? Encontramos eco na assertiva de Diana Jerusalinsky (2011, p. 253): "TDA possivelmente não reflete, pois, déficit de atenção das crianças, mas a falta de atenção às suas necessidades por parte dos adultos". Falta de atenção esta referendada pela advertência do DSM-IV de que os sintomas podem não se manifestar durante a consulta médica e na recomendação para o clínico indagar sobre o comportamento do sujeito em diversos contextos, reunindo informações de múltiplas fontes, como pais e professores, porém, dentre essas fontes, o próprio sujeito fica excluído.

Chama atenção, ainda, a importância que o DSM apõe sobre o desempenho escolar na definição do diagnóstico, citando claramente o contexto escolar por oito vezes, conforme sublinhado no Quadro 1, que apresenta os critérios diagnósticos do TDAH. No entanto algumas incongruências sobre o desempenho acadêmico podem ser observadas:

Em média, os indivíduos com Transtorno do Déficit de Atenção/Hiperatividade atingem menor grau de escolarização e realizações profissionais mais modestas que seus pares. Também em média, o nível intelectual, avaliado por testes individuais de Ql é vários pontos inferior em crianças com este transtorno quando comparadas com seus pares. Ao mesmo tempo, evidencia-se uma grande variabilidade de Q.I.: indivíduos com o transtorno podem demonstrar um desenvolvimento intelectual na faixa acima da média ou superdotada. Em 
sua forma grave, o transtorno é acentuadamente incapacitante, afetando o ajustamento social e escolar. (APA, 2002, p. 114, grifos nossos).

O DSM-IV parece colocar-se como um oráculo sobre a vida dos sujeitos diagnosticados, pois afirma que, em média, eles têm escolarização menor. Não fica claro, no texto do manual, a partir de qual metodologia essa média foi aferida, se existiu um grupo controle nestes estudos, enfim, o texto carece de uma apresentação de dados que possibilitem, a quem o consulta, ter uma visão crítica acerca do diagnóstico. Em seguida, outra incoerência é apresentada: os testes que avaliam o quociente de inteligência apresentam uma variabilidade muito grande nos sujeitos com o diagnóstico de TDAH. Abre-se, assim, o questionamento: em que se justifica um grupo com vários pontos de QI inferior e outro grupo, com o mesmo transtorno, mas com desenvolvimento intelectual na faixa acima da média ou superdotada?

Por fim, vale ressaltar que o TDAH, segundo o DSM-IV, se apresenta em comorbidade de cinquenta por cento para o Transtorno Desafiador de Oposição ou Transtorno da Conduta, transtornos relacionados ao ajustamento dos sujeitos às normas sociais. Referindo-se novamente à importância da escola, o manual psiquiátrico estabelece como outra fonte de informação os boletins escolares e avisa que "geralmente, o transtorno é diagnosticado pela primeira vez durante as primeiras séries, quando o ajustamento à escola está comprometido" (APA, 2002, p. 116).

Apesar de todas as controvérsias sobre os critérios diagnósticos propostos pelo DSM-IV para o TDAH, diversos instrumentos de avaliação diagnóstica se desenvolveram e são utilizados para o diagnóstico do TDAH, alguns deles disponíveis em meios eletrônicos e de acesso gratuito a qualquer sujeito, como o questionário Swanson, Nolan e Pelham IV (SNAP-IV). Majoritariamente, esaes instrumentos ancoram-se na observação da criança e são destinados ou aos professores ou às famílias dessas crianças ou adolescentes. Outro exemplo desse tipo de instrumento é o teste psicológico Escala de transtorno de déficit de atenção e hiperatividade - versão para professores (BENCZIK, 2000), editado pela Casa do Psicólogo.

As incoerências nos critérios diagnósticos do TDAH são analisadas por Moysés e Collares (2011) a partir da revisão de estudos provenientes da medicina e concluem que, mesmo nesse campo, o TDAH e a dislexia, transtornos relacionados ao não aprender, não encontram consenso. Neste trabalho, as autoras 
realizam um resgate histórico, apontando que os estudos do TDAH e o tratamento com anfetaminas não são tão recentes como se apregoa, mas têm mudado de apresentação com o transcorrer dos anos. Assim, conforme o momento histórico, o não aprender recebeu a classificação psicopatológica de Lesão Cerebral Mínima, Disfunção Cerebral Mínima, Déficit de Atenção, Déficit de Atenção com Hiperatividade e, finalmente, TDAH.

É importante salientar que as autoras, partindo de um posicionamento crítico, entendem o TDAH e a dislexia como constructos ideológicos "sem qualquer embasamento científico, que muda constantemente de nome e aparência, sem que se altere em sua essência, isto é, [trata-se da] biologização de seres culturais, datados e situados" (MOYSÉS; COLLARES, 2011, p. 82). Dentre os principais problemas apontados pelas autoras na revisão das pesquisas sobre o TDAH, encontram-se erros metodológicos nas pesquisas como estudos com sujeitos diagnosticados com TDAH ou dislexia na ausência de critérios diagnósticos precisos para essas pretensas doenças e estudos experimentais sem grupo-controle.

Ampliando a discussão sobre o TDAH, tanto o trabalho de Moysés e Collares (2011) como outros estudos, preocupam-se com o aumento vertiginoso do consumo do cloridrato de metilfenidato, droga da família das anfetaminas utilizada para o tratamento do TDAH. De acordo com o Conselho Federal de Psicologia (2012):

No Brasil, por exemplo, o metilfenidato, substância dada para crianças e adolescentes com a pretensão de diminuir o chamado 'déficit de atenção' na escola, subiu de 70.000 caixas vendidas em 2000 para dois milhões de caixas em 2010, inserindo o Brasil no segundo maior consumidor dessa droga no mundo, perdendo somente para os Estados Unidos.

Embora, a revisão dos estudos sobre a eficácia e os riscos do uso de anfetaminas por crianças e adolescentes mostrem-se inconclusos e "os efeitos terapêuticos tão divulgados, sempre apresentados como benéficos, constituem na verdade sinais de toxicidade das drogas", o consumo de tais medicamentos tem crescido assombrosamente (MOYSÉS; COLLARES, 2010, p. 102, grifo das autoras).

Diana Jerusalinky, em 2011, apresenta o modo de funcionamento dos psicoestimulantes em crianças, recorrendo a uma revisão bibliográfica de estudos sobre o uso desses medicamentos tanto em animais, como em crianças. Segundo a autora, tais estudos revelam que os psicoestimulantes "suprimem os comportamentos espontâneos e podem incrementar comportamentos obsessivos" 
(JERUSALINSKY, 2011, p. 247). Entretanto esses efeitos colaterais da medicação, como redução de comportamentos de exploração, curiosidade, socialização e do brincar, assim como o envolvimento em atividades muito limitadas e focadas, são tomados como sinais de melhora por parte dos educadores, pais e clínicos. Para a autora, outro efeito observado nas famílias com crianças medicadas com psicoestimulantes é a perda do interesse dos adultos pelas crianças depois do início da medicação e, por consequência, a perda do senso de responsabilidade e autodeterminação por parte da criança (JERUSALINSKY, 2011, p. 248).

A autora consultada salienta que o diagnóstico de TDAH, na maioria dos casos, é outorgado a crianças que entraram em conflito com as expectativas e demandas dos ambientes que estão inseridas na maior parte do tempo, na escola e na família. O diagnóstico surge, então, como uma resposta que deixa de refletir sobre a realidade das relações estabelecidas nesses ambientes e atribui a uma suposta alteração no cérebro a causa desses conflitos. Nesse contexto, a medicação surge como uma resposta coercitiva ao conflito (JERUSALINSKY, 2011).

O psicanalista Alfredo Jerusalinsky (2006) faz uma crítica quanto à base fenomenológica do diagnóstico e à autonomia dada aos sintomas do TDAH. Embora suas análises partam de uma matriz teórica diferente dos estudos de Moysés e Collares (2011), as conclusões de Jerusalinsky acerca do TDAH e do uso do metilfenidato são semelhantes. Assim, o autor salienta como os resultados positivos do uso do medicamento são focalizados pela indústria farmacêutica em detrimento do alto percentual (38\%) de crianças para quem o tratamento medicamentoso isolado não apresentou nenhum efeito. O texto consultado argumenta ainda que metodologicamente "não é sustentável a conclusão acerca do uso preferencial da medicação. Ou, pelo menos, não do uso isolado da medicação. Não se sustenta que seja apresentada como o tratamento central" (JERUSALINSKY, 2006, p. 27).

Quanto ao diagnóstico do TDAH, para Jerusalinsky (2006), a perspectiva médica, embasada em um diagnóstico fenomenológico, aparentemente tomam a atenção e a atividade como entidades autônomas do sistema nervoso central. Entretanto, segundo este autor, diversos estudos psicológicos afirmam a correlação entre o desenvolvimento das funções psíquicas e a matriz simbólica fornecida pelas relações sociais. Desse modo, outro questionamento à abordagem médico-fenomenológica do TDAH se faz necessária: "Será que as dificuldades sociais são uma consequência da síndrome ou será que essa dificuldade social é indicadora 
do ponto central da etiologia do que ocorre com essas crianças?" (JERUSALINSKY, 2006, p. 40).

Destarte nota-se a importância da experiência da passagem pela relação com o outro para o desenvolvimento das funções psíquicas superiores, dentre elas, a atenção e a memória que estão em suposto prejuízo no TDAH. É necessário considerar o sujeito que faz a função funcionar, sem dar às funções psicológicas um estatuto de autonomia no diagnóstico e tratamento. Em tempos de respostas prontas e embaladas em comprimidos, faz-se urgente uma escuta dos sujeitos em vez do uso indiscriminado de medicação, ancorado num diagnóstico que exclui a escuta do sujeito e de seu entorno, silenciando os conflitos decorrentes da vivência humana.

\section{CONSIDERAÇÕES FINAIS}

Obviamente, esta revisão bibliográfica não esgota a investigação da vasta produção científica nacional dos últimos anos sobre a medicalização e o TDAH, entretanto trouxe contribuições importantes à definição desses conceitos para o embasamento de duas pesquisas. A primeira, produzida em nível de pós-graduação lato sensu em Educação, apresentou o estado do conhecimento produzido nos programas de pós-graduação em Educação e Psicologia do Estado de Mato Grosso do Sul sobre essa temática. A segunda pesquisa foi realizada na pós-graduação stricto sensu em Educação, nível mestrado, e buscou compreender as funções do diagnóstico médico e psicológico de queixas escolares, dentre elas o TDAH, para os professores das séries iniciais do ensino fundamental em uma cidade no interior de Mato Grosso do Sul, a partir do viés da medicalização.

Este trabalho subsidia ainda uma visão crítica da inserção das ciências da saúde na Educação, elucidando os efeitos nefastos da medicalização da vida e da Educação, como a estigmatização dos sujeitos e os consequentes sentimentos de desvalia e a desresponsabilização do contexto escolar, uma vez que a causa apontada para as dificuldades de escolarização são biológicas, portanto, individuais. Nesse escopo, frisamos o alerta da psicanalista Diana Jerusalinsky, de olharmos para além dos transtornos mentais que atravessam o campo educativo como respostas às contradições deste: "TDA possivelmente não reflete, pois, déficit de atenção das crianças, mas a falta de atenção às suas necessidades por parte dos adultos" (JERUSALINSKY, 2011, p. 253, grifos nossos). 


\section{REFERÊNCIAS}

AMERICAN PSYCHIATRIC ASSOCIATION (APA). Manual diagnóstico e estatístico de transtornos mentais: DSM-5. 5. ed. Porto Alegre: Artmed, 2016.

. Manual diagnóstico e estatístico de transtornos mentais: DSM-IV-TR TM texto revisado. 4. ed. Porto Alegre: Artmed, 2002.

BENCZIK, Edyleine Bellini Peroni. Manual da escala de transtorno de déficit de atenção/ hiperatividade: versão para professores. Itatiba, SP: Casa do Psicólogo, 2000.

BRASIL. Decreto n. 7.611, de 17 de novembro de 2011. Dispõe sobre a educação especial, o atendimento educacional especializado e dá outras providências. Disponível em: <http://www.planalto.gov.br/ccivil_03/_Ato2011-2014/2011/Decreto/D7611.htm>. Acesso em: 12 nov. 2013.

COLLARES, Cecília Azevedo Lima; MOYSÉS, Maria Aparecida Affonso. Preconceitos no cotidiano escolar: a medicalização do processo ensino-aprendizagem. In: CONSELHO REGIONAL DE PSICOLOGIA DE SÃO PAULO; GRUPO INTERINSTITUCIONAL QUEIXA ESCOLAR. Medicalização de crianças e adolescentes: conflitos silenciados pela redução de questões sociais a doença de indivíduos. São Paulo: Casa do Psicólogo, 2011. p. 193-213.

CONSELHO FEDERAL DE PSICOLOGIA (CFP). Subsídios para a campanha não à medicalização da vida: medicalização da educação. 2012. Disponível em: <http://site.cfp.org.br/ wp-content/uploads/2012/07/Caderno_AF.pdf > Acesso em: 10 abr. 2014.

FENDRIK, Silvia. O DSM-IV, uma metafísica comportamental? In: JERUSALINSKY, Alfredo; FENDRIK, Silvia (Org.). O livro negro da psicopatologia contemporânea. São Paulo: Via Lettera, 2011, p. 29-37.

GUARIDO, Renata. A biologização da vida e algumas implicações do discurso médico sobre a educação. In: CONSELHO REGIONAL DE PSICOLOGIA DE SÃO PAULO; GRUPO INTERINSTITUCIONAL QUEIXA ESCOLAR. Medicalização de crianças e adolescentes: conflitos silenciados pela redução de questões sociais a doença de indivíduos. São Paulo: Casa do Psicólogo, 2011. p. 27-39.

IZAGUIRRE, Guilhermo. Elogio do DSM-IV. In: JERUSALINSKY, Alfredo; FENDRIK, Silvia (Org.). O livro negro da psicopatologia contemporânea. São Paulo: Via Lettera, 2011. p. 13-22.

JERUSALINSKY, Alfredo. Diagnóstico de déficit de atenção, o que pode dizer a psicanálise? Correio da APPOA, Porto Alegre, n. 144, p. 24-41, mar. 2006.

JERUSALINSKY, Diana A. Trata-se de caçar o caçador? In: JERUSALINSKY, Alfredo; FENDRIK, Silvia (Org.). O livro negro da psicopatologia contemporânea. São Paulo: Via Lettera, 2011. p. 245-58.

MOYSÉS, Maria Aparecida Affonso; COLLARES, Cecília Azevedo Lima. Dislexia e TDAH: uma análise a partir da ciência médica. In: CONSELHO REGIONAL DE PSICOLOGIA DE SÃO 
PAULO (CRPSP); GRUPO INTERINSTITUCIONAL QUEIXA (GIQE). Medicalização de crianças e adolescentes: conflitos silenciados pela redução de questões sociais a doenças de indivíduos. São Paulo: Casa do Psicólogo, 2011. p. 71-110.

POLANCZYK, Guilherme Vanoni; ROHDE, Luis Augusto. Transtorno de déficit de atenção e hiperatividade. In: FORLENZA; Orestes Vicente; MIGUEL, Eurípedes Constantino (Org.). Compêndio de Clínica Psiquiátrica. Barueri, SP: Manole, 2012. p. 220-39.

SAVIANI, Dermeval. Escola e democracia: teorias da educação, curvatura da vara, onze teses sobre a educação política. 36. ed. rev. Campinas, SP: Autores Associados, 2003. (Coleção Polêmicas de nosso tempo, v. 5).

SNAP-IV. Versão em português validada por MATTOS, P. et al, 2005. Disponível em: <www. tdah.og.br>. Acesso em: 25 abr. 2014.

WERNER JÚNIOR, Jairo. A medicalização da vida do deficiente como barreira para a inclusão social. In: TUNES, Elizabeth; BARTTHOLO, Roberto. Nos limites da ação: preconceito, inclusão e deficiência. São Carlos: EdUFSCAR, 2007. p. 69-78.

\section{Sobre as autoras:}

Mayara Karolina Alvarenga Recaldes Gomes Coutinho: Mestre em Educação pela Universidade Estadual de Mato Grosso do Sul (UEMS). Psicóloga da Universidade Federal de Mato Grosso do Sul, Campus de Paranaíba (UFMS/CPAR). E-mail: mayarakargcoutinho@gmail.com

Doracina Aparecida de Castro Araujo: Orientadora. Docente adjunta do Programa de Pós-Graduação em Educação, nível de mestrado e dos cursos de Especialização em Educação e Pedagogia da Universidade Estadual de Mato Grosso do Sul (UEMS), Unidade Universitária de Paranaíba. E-mail: doracina@gmail.com

\section{Recebido em maio de 2017}

Aprovado em novembro de 2017 
